\title{
Pharmacist medication instructions are associated with continued medication self- management in older adults: a retrospective observational study
}

Eiji Kose ${ }^{1 *}$, Hidetatsu Endo ${ }^{2}$, Hiroko Hori ${ }^{2}$, Shingo Hosono ${ }^{2}$, Chiaki Kawamura², Yuta Kodama²,

Takashi Yamazaki $^{2}$ and Nobuhiro Yasuno ${ }^{1,3}$

\begin{abstract}
Background: Various factors are related to self-management of medication. However, few reports comprehensively examine the factors related to patients, medication levels, and other factors related to the recuperative environment, such as family support. The aim of this study was to investigate factors affecting the continuation of medication self-management among hospitalized older adults receiving convalescent rehabilitation.

Methods: We conducted a retrospective observational study with 274 consecutive patients newly admitted to the convalescent rehabilitation wards at a single hospital in Japan between January 2017 and May 2018. Participants who were assessed for their ability to take their medication using the Japanese Regimen Adherence Capacity Tests, were deemed to be self-manageable, and were able to successfully continue to self-manage their medication from admission to discharge were categorized as the "continuation group," and those who were not able to continue were categorized as the "non-continuation group." We analyzed the groups' demographic data, laboratory data, and Functional Independence Measure. The primary outcome was the continuation of medication selfmanagement from admission to discharge.
\end{abstract}

Results: After enrollment, 134 patients (median age 82 years; 62.7\% women) were included in the final analysis. Some $60.4 \%$ of eligible patients were able to maintain medication self-management during their hospitalization. The multiple logistic regression analysis for the continuation of medication self-management during hospitalization after adjusting for confounding factors revealed that pharmacist medication instructions were independently and positively correlated with successful continuation of medication self-management (odds ratio: 1.378; $95 \%$ confidence interval 1.085-1.831; $p=0.0076$ ).

Conclusion: Successful continuation of medication self-management is associated with pharmacist medication instructions among hospitalized older adults undergoing rehabilitation.

Trail registration: The Ethics Committee's registration number is "TGE01216-066".

Keywords: Convalescent rehabilitation ward, Medication self-management, Older adults, Pharmacist medication instructions

\footnotetext{
* Correspondence: kose.eiji@med.teikyo-u.ac.jp

'Department of Pharmacy, Teikyo University School of Medicine University Hospital, 2-11-1 Kaga, Itabashi-ku, Tokyo 173-8606, Japan

Full list of author information is available at the end of the article
}

(c) The Author(s). 2021 Open Access This article is licensed under a Creative Commons Attribution 4.0 International License, which permits use, sharing, adaptation, distribution and reproduction in any medium or format, as long as you give appropriate credit to the original author(s) and the source, provide a link to the Creative Commons licence, and indicate if changes were made. The images or other third party material in this article are included in the article's Creative Commons licence, unless indicated otherwise in a credit line to the material. If material is not included in the article's Creative Commons licence and your intended use is not permitted by statutory regulation or exceeds the permitted use, you will need to obtain permission directly from the copyright holder. To view a copy of this licence, visit http://creativecommons.org/licenses/by/4.0/ The Creative Commons Public Domain Dedication waiver (http://creativecommons.org/publicdomain/zero/1.0/) applies to the data made available in this article, unless otherwise stated in a credit line to the data. 


\section{Background}

The primary purpose of the convalescent rehabilitation ward is to provide intensive rehabilitation for patients with stroke, femur fracture, and hospital-associated deconditioning. The second aim is to improve and maintain ADL to help patients return home. The convalescent rehabilitation ward is characterized by a long hospital stay and a significant number of elderly patients. Thus, not only the direct cause of their hospitalization, but also their underlying medical condition prior to admission makes many elderly patients prone to polypharmacy due to the high number of medications they take. A previous report had shown that $33 \%$ of patients in the convalescent rehabilitation ward were found to have polypharmacy [1]. Polypharmacy is a known cause of poor medication adherence [2]. Approximately 34\% of patients with stroke failed to maintain their medication after 1 year of discharge [3]. Poor medication adherence has a negative impact on the treatment and control of disease and also affects the occurrence of adverse effects due to medications.

Many patients in the convalescent rehabilitation ward recuperate at home after discharge; therefore, it is important to improve their medication knowledge during hospitalization to maintain long-term medication selfmanagement. Previously, patient-level barriers associated with medication self-management included the ability to ensure self-care, interest attached to a stroke event, and knowledge of stroke and medication. Medication-level barriers included beliefs about medication and beliefs about how pills work, medication routines, changing medications, regimen complexity, and burden of treatment [4]. Some studies have reported that patients seek psychological and emotional support in the process of self-management and that they also sometimes need family support; the influence of the recuperative environment must be considered in the context of medication self-management $[5,6]$. Although various factors are related to self-management of medication, few reports have comprehensively examined factors related to patients, medication levels, and other factors related to the recuperative environment, such as family support.

In this study, we examined the factors affecting the continuation of medication self-management in elderly patients in the convalescent rehabilitation ward, taking into account factors related to patients and their medication levels as well as factors in the recuperative environment, such as family support.

\section{Methods}

\section{Study design and participants}

A retrospective observational study was performed on 274 consecutive participants admitted to the convalescence rehabilitation ward at Ogaki Tokushukai Hospital between January 2017 and May 2018. The inclusion criterion was age $\geq 65$ years. Participants who were selfmanaging their medication at admission, with severe communication difficulties, with severe psychiatric disorders, with severe higher brain dysfunction or cognitive decline, who refused to self-manage their medication, who had no prescription medication, who were institutional/family-managed, or who were health care providers, readmitted participants, or who were clearly unable to self-manage for other reasons were excluded.

\section{Investigation items}

Data on the participants' basic information were collected from their medical records at admission and discharge, as appropriate. This information included their age, sex, length of stay, body weight, BMI, primary diagnosis, comorbidities, presence of family cooperation, HDS-R, upper limb paralysis, higher brain dysfunction, vision loss, number of medications at admission, medication instruction, number of medication instructions, and FIM.

Laboratory data were also collected from medical records at admission and discharge. These included albumin and CRP levels.

\section{Assessment indications}

Indicators of ADL such as FIM and the Barthel index are used for evaluation during the recovery period [7]. In particular, the reliability of FIM is confirmed in a metaanalysis of 11 studies [8]. Therefore, we used FIM as the ADL measurement. The FIM score, which includes 13 lower-order items regarding FIM-M and 5 lower-order items regarding FIM-C, is one of the most common measures of ADL [8]. Each item is scored on a scale of 1 point (total assistance) to 7 points (complete independence). The FIM-T score therefore ranges from 18 to 126 points. FIM scores were determined at admission and discharge by a multidisciplinary rehabilitation team, including a rehabilitation physician, registered dietitian, nurse, physical therapist, occupational therapist, speech language-hearing therapist, and pharmacist. Based on clinical judgment, appropriate rehabilitation was offered to all participants, regardless of their FIM score, stroke severity, or length of stay.

In this study, we used the J-RACT to assess the patient's ability to take medication. The J-RACT is a medication assessment test to evaluate the ability of elderly people with disease in Japan to take medication and to provide them with appropriate medication instructions. J-RACT was originally developed based on the report by Fitten et al. [2]. However, the method and content of J-RACT were completely redesigned to conform to Japanese medication. J-RACT has been used to examine the ability of prevalent older patients with chronic cardiovascular 
disease to take medication, mainly in outpatient and inpatient settings [9]. The J-RACT consists of 4 simple questionnaires for the elderly on (1) visual and auditory acuity; (2) ability to understand medication (understanding of dosage and administration); (3) ability to work with medication (manual dexterity); and (4) ability to manage medication (long-term management at home) [9]. The ability to manage medications (long-term management at home) was assessed by the RCS. The RCS is a medication management assessment scale that uses 5 medications with various dosing methods and medication bags and asks questions about the 5 dosing methods using an interview method. The RCS is a 10-point scale divided into 4 levels based on scores: normal ability (10 points), caution required ( 9,8 points), training required ( 7,6 points), and assistance required (5 points or less) [10]. A multidisciplinary team, including physicians, pharmacists, and nurses with long experience in convalescent rehabilitation, comprehensively assessed items (1) to (4) and determined whether the patient could self-manage his or her medication. Participants who were assessed for their ability to take their medication using the J-RACT, were deemed self-manageable, and were able to successfully continue to manage their medication from admission to discharge were categorized as the "continuation group," and those who were not able to continue were categorized as the "non-continuation group."

\section{Outcome measurement}

The primary outcome of this study was the continuation of successful medication self-management from admission to discharge.

\section{Statistical analysis}

All statistical analyses were performed using JMP Pro (Version 13, SAS Institute, Cary, NC, USA). Data with a normal distribution were described as mean \pm standard deviation. If not normally distributed, data were described as median (interquartile range 25 th-75th percentiles). A $p$-value $<0.05$ was considered statistically significant.

Student's $t$-test, the Mann-Whitney U test, and $\chi^{2}$ test were used to analyze the differences between groups. A multiple logistic regression analysis was used to analyze the factors influencing the continuation of medication self-management during hospitalization. Factors found to be significantly associated in the univariate analysis of continued medication self-management (age, FIM-C at admission, number of medication instructions, HDS-R, albumin level at admission, hypertension, and dyslipidemia) were used as explanatory variables in the multiple logistic regression analysis. Only 1 variable, which was more reasonable from a medical and pharmacological point of view, was included in the multiple logistic regression analysis if there was a strong internal correlation between the explanatory variables $(p<0.01)$. We drew a ROC curve to assess the cut-off value for the number of episodes of medication instruction associated with continued medication self-management. We calculated sensitivity, specificity, accuracy, true positive, true negative, false positive, false negative, F1 value, and MCC [11] to further assess the number of episodes of medication instruction that predicts the continued medication self-management.

\section{Results \\ Study populations}

This retrospective observational study with 274 consecutive participants excluded 23 patients who were selfmanaging their medication at admission, 1 patient with severe communication difficulties, 6 patients with severe psychiatric disorders, 70 patients with severe higher brain dysfunction or cognitive decline, 16 patients who refused to self-manage their medication, 2 patients with no prescription medication, 9 patients under institutional or family management, 1 health care provider, 2 patients who were readmitted to the hospital, and 10 patients who were clearly unable to self-manage for other reasons. Ultimately, 134 participants with a median age of 82 years (interquartile range $76-85$ years; 84 women) were included, of whom $10(7.5 \%)$ had cerebral infarction, 7 (5.2\%) had intracerebral hemorrhage, 2 $(1.5 \%)$ had subarachnoid hemorrhage, $104(77.6 \%)$ had osteoporosis-related diseases, $1(0.7 \%)$ had hospitalassociated deconditioning, and 10 (7.5\%) had other conditions.

\section{Descriptive and univariate analyses}

Table 1 shows the demographic characteristics of the patients based on the presence $(n=81)$ and absence $(n=$ 53) of continued medication self-management during hospitalization. BMI at admission, the diagnosis of hypertension and dyslipidemia, HDS-R, the number of medication instructions, FIM-T, FIM-C at admission, and FIM-T, FIM-M, and FIM-C at discharge were significantly higher in the continuation group compared with the non-continuation group. Conversely, age was significantly higher in the non-continuation group compared with the continuation group. There was no significant difference between the 2 groups in any of the other items.

Regarding clinical laboratory data, albumin level at admission was significantly higher in the continuation group compared with the non-continuation group. There was no significant difference in CRP on admission between the 2 groups.

\section{Multiple logistic regression analysis}

The multiple logistic regression analysis for the continuation of medication self-management during hospitalization after adjusting for potential confounders, including age, 
Table 1 Baseline of demographic characteristics and laboratory data

\begin{tabular}{|c|c|c|c|c|}
\hline Characteristic & $\begin{array}{l}\text { All patients } \\
(n=134)\end{array}$ & $\begin{array}{l}\text { Continuation group } \\
(n=81)\end{array}$ & $\begin{array}{l}\text { Non-continuation group } \\
(n=53)\end{array}$ & $p$ value \\
\hline Age (y) & $82(76-85)$ & $80(73-84)$ & $83(80.5-88)$ & $0.0013^{+}$ \\
\hline Gender $n,(\%)$ & & & & $0.4166^{\S}$ \\
\hline Male & $50(37.3)$ & $28(34.6)$ & $22(41.5)$ & \\
\hline Female & $84(62.7)$ & $53(65.4)$ & $31(58.5)$ & \\
\hline Length of stay (d) & $42(29-55.8)$ & $40(28.5-58.5)$ & $45(29-54)$ & $0.5571^{\dagger}$ \\
\hline Body weight at admission (kg) & $50(44-60)$ & $51(43.1-63.9)$ & $48.2(42-56.8)$ & $0.0502^{+}$ \\
\hline BMI at admission $\left(\mathrm{kg} / \mathrm{m}^{2}\right)$ & $21.4(18.8-24.1)$ & $22.1(19.2-25.1)$ & $20.7(17.8-23.2)$ & $0.0115^{\dagger}$ \\
\hline Primary diagnosis $n,(\%)$ & & & & $0.6419^{\S}$ \\
\hline Cerebral infraction & $10(7.5)$ & $6(7.4)$ & $4(7.6)$ & \\
\hline Intracerebral hemorrhage & $7(5.2)$ & $3(3.7)$ & $4(7.6)$ & \\
\hline Subarachnoid hemorrhage & $2(1.5)$ & $2(2.5)$ & $0(0)$ & \\
\hline Osteoporosis-related disease & $104(77.6)$ & $64(79.0)$ & $40(75.4)$ & \\
\hline Hospital-associated deconditioning & $1(0.7)$ & $1(1.2)$ & $0(0)$ & \\
\hline Others & $10(7.5)$ & $5(6.2)$ & $5(9.4)$ & \\
\hline \multicolumn{5}{|l|}{ Comorbid conditions $n,(\%)$} \\
\hline Cardiac disease & $18(13.3)$ & $11(13.6)$ & $7(13.2)$ & $0.9507^{\S}$ \\
\hline Diabetes mellitus & $30(22.2)$ & $15(18.5)$ & $15(28.3)$ & $0.1840^{\S}$ \\
\hline Hypertension & $87(64.4)$ & $58(71.6)$ & $29(54.7)$ & $0.0452^{\S}$ \\
\hline Dyslipidemia & $40(29.6)$ & $31(38.3)$ & $9(17)$ & $0.0085^{\S}$ \\
\hline Dementia & $2(1.5)$ & $0(0)$ & $2(3.8)$ & $0.0782^{\S}$ \\
\hline Epilepsy & $3(2.2)$ & $1(1.2)$ & $2(3.8)$ & $0.3313^{\S}$ \\
\hline Parkinson's disease & $2(1.5)$ & $1(1.2)$ & $1(1.9)$ & $0.7608^{\S}$ \\
\hline Family cooperation $n,(\%)$ & $117(87.3)$ & $72(88.9)$ & $45(84.9)$ & $0.4981^{\S}$ \\
\hline HDS-R & $25(21-28)$ & $26(23-28)$ & $23(19-26)$ & $0.0011^{\S}$ \\
\hline Upper limb paralysis $n$, (\%) & $22(16.3)$ & $12(14.8)$ & $10(18.9)$ & $0.5357^{\S}$ \\
\hline Higher brain dysfunction $n$, (\%) & $24(17.9)$ & $9(11.1)$ & $15(28.3)$ & \\
\hline Vision loss $n,(\%)$ & $14(10.4)$ & $9(11.1)$ & $5(9.4)$ & $0.7563^{\S}$ \\
\hline No. of medications at admission & $6.7 \pm 3.5$ & $6.8 \pm 3.2$ & $6.8 \pm 3.8$ & $0.8388^{\S}$ \\
\hline medication instruction $n,(\%)$ & $134(100)$ & $81(100)$ & $53(100)$ & $0.2146^{\S}$ \\
\hline No. of medication instructions & $6(4-9)$ & $7(5-10)$ & $5(2.5-7)$ & $<.0001^{\dagger}$ \\
\hline \multicolumn{5}{|l|}{ FIM at admission (points) } \\
\hline FIM-M & $50(33-60)$ & $52(37.5-59)$ & $46(29.5-63.6)$ & $0.1497^{\dagger}$ \\
\hline FIM-C & $30(26-35)$ & $32(29-35)$ & $28(21.5-33)$ & $0.0011^{\dagger}$ \\
\hline $\mathrm{FIM}-\mathrm{T}$ & $79(63-92)$ & $82(69.5-93)$ & $73(57.5-91.5)$ & $0.0166^{\dagger}$ \\
\hline \multicolumn{5}{|l|}{ FIM at discharge (points) } \\
\hline FIM-M & $82(74-86)$ & $83(76.5-86)$ & $78(67-85)$ & $0.0084^{+}$ \\
\hline FIM-C & $34(30-35)$ & $35(32-35)$ & $30(26-34.5)$ & $<.0001^{+}$ \\
\hline FIM-T & $114(103.5-119.5)$ & $117(108.3-121)$ & $109(93.5-115.5)$ & $0.0004^{+}$ \\
\hline \multicolumn{5}{|l|}{ Clinical laboratory data at admission } \\
\hline Alb (g/dL) & $3.4 \pm 0.6$ & $3.5 \pm 0.5$ & $3.2 \pm 0.7$ & $0.0097^{\ddagger}$ \\
\hline $\mathrm{CRP}(\mathrm{mg} / \mathrm{dL})$ & $0.46(0.19-1.30)$ & $0.41(0.11-1.15)$ & $0.68(0.27-1.39)$ & $0.2354^{+}$ \\
\hline
\end{tabular}


FIM-C at admission, the number of medication instructions, HDS-R, albumin level at admission, hypertension, and dyslipidemia is shown in Table 2. There was no multicollinearity between the variables. The multiple logistic regression showed that the number of medication instructions was independently and positively associated with the continuation of medication self-management (odds ratio [OR] 1.378; 95\% confidence interval [CI] $1.085-1.831 ; p=0.0076$ ), age (OR 0.888; 95\% CI $0.780-$ 0.993; $p=0.0363$ ), FIM-C at admission (OR 1.167; 95\% CI 1.025-1.353; $p=0.0175$ ), and hypertension (OR 5.902; 95\% CI 1.485-29.500; $p=0.0106$ ) (Table 2).

\section{Cut-off value for the necessary number of episodes of medication instruction}

The result of the ROC curve analysis is shown in Fig. 1. Table 3 shows the predictive ability of the predictive number of episodes of medication instruction for continued medication self-management. A cut-off value $\geq 6$ episodes for ROC curve analysis corresponded to 69.1, 67.9, $77.9 \%, 0.73$, and 0.36 sensitivity, specificity, accuracy, F1 value, and MCC, respectively. Meanwhile, the continued medication self-management cut-off value $\geq 5$ episodes had larger values of sensitivity, specificity, F1 value, and MCC, respectively compared to $\geq 6$ or $\geq 7$ episodes. Thus, we determined that the cutoff value was $\geq 5$ episodes.

\section{Discussion}

This study demonstrated that the number of medication instructions by pharmacists were significantly associated with successful continued medication self-management. In other words, pharmacists were found to positively affect patients' continued medication self-management when they provided medication instructions. Second, the cut-off value for medication instruction episodes required by the pharmacist for continued medication selfmanagement was 5 . In other words, when pharmacists

Table 2 Multiple logistic regression analysis for continuation of self-management of medications

\begin{tabular}{llll}
\hline Variable & $\begin{array}{l}\text { Adjusted } \\
\text { Odds ratio }\end{array}$ & $\begin{array}{l}\mathbf{9 5 \% ~ C l} \\
\text { (Lower-Upper) }\end{array}$ & $\boldsymbol{p}$ value \\
\hline Age & 0.888 & $0.780-0.993$ & 0.0363 \\
FIM-C at admission & 1.167 & $1.025-1.353$ & 0.0175 \\
$\begin{array}{l}\text { No. of medication } \\
\text { instructions }\end{array}$ & 1.378 & $1.085-1.831$ & 0.0076 \\
HDS-R & 1.057 & $0.889-1.275$ & 0.5348 \\
Alb at admission & 0.552 & $0.172-1.660$ & 0.2844 \\
Hypertension & 5.902 & $1.485-29.500$ & 0.0106 \\
Dyslipidemia & 3.834 & $0.774-25.224$ & 0.1021 \\
\hline
\end{tabular}

Abbreviations: Alb Albumin, BMI Body mass index, Cl Confidence interval, FIM-C Functional Independence Measure-cognitive, HDS- $R$ Hasegawa dementia rating scale-revised

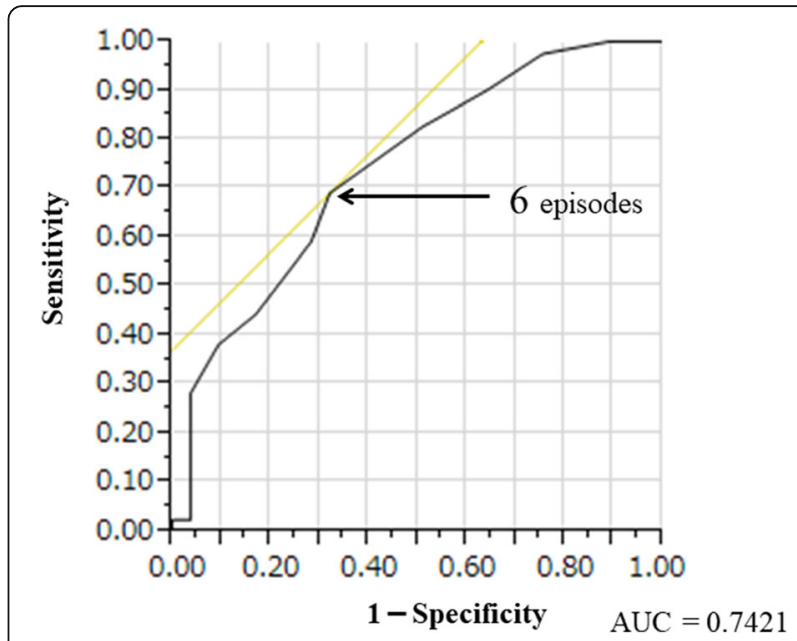

Fig. 1 A Cut-off value for the necessary number of episodes of medication instruction for continued medication self-management due to ROC curve analysis

repeatedly (5 times) instructed patients on the efficacy and dosage of medications, they were able to maintain successful medication self-management during their hospitalization.

Most of the patients admitted to the convalescent rehabilitation ward are elderly. Therefore, many patients have underlying medical conditions that predate their admission, in addition to the direct cause of their admission. Thus, these patients require long-term adherence to a medication regimen. However, patients admitted to the convalescent rehabilitation ward are often unable to continue their medication self-management and find it difficult to continue taking their medication due to cognitive decline, higher brain dysfunction, and a lack of disease or drug knowledge. Furthermore, from the perspective of rehabilitation pharmacotherapy [12], ADLs may be reduced due to the development of adverse drug events [13-16], resulting in the inability to continued medication self-management. Discontinuing medication at the patient's own discretion, such as stopping antihypertensive medication, can worsen symptoms and delay their discharge from the hospital. The ability of patients to self-manage their medication and adherence is therefore important to maintaining their ADL.

Medication management during hospitalization has been reported to affect medication adherence after discharge [17]. Sendt et al. had reported that positive attitudes toward medication therapy and disease awareness lead to improved medication self-management and better adherence [18]. In the convalescent rehabilitation ward, due to the nature of the particular condition, such as cognitive decline, higher cerebral dysfunction, or upper extremity paralysis, nurses frequently administer medications to patients for certainty and safety reasons. 
Table 3 The verification of the cutoff value for the number of episodes of medication instruction

\begin{tabular}{llllllllll}
\hline & TP & FP & TN & FN & Sensitivity & Specificity & Accuracy & F1 value & MCC \\
\hline$\geq 7$ episodes & 21 & 9 & 28 & 10 & 0.677 & 0.757 & 0.721 & 0.689 & 0.436 \\
$\geq 6$ episodes & 56 & 17 & 36 & 25 & 0.691 & 0.679 & 0.779 & 0.727 & 0.364 \\
$\geq 5$ episodes & 36 & 6 & 16 & 10 & 0.783 & 0.727 & 0.765 & 0.818 & 0.491 \\
\hline
\end{tabular}

Abbreviations: FN False Negative, FP False Positive, TN True Negative, TP True Positive, MCC Matthews Correlation Coefficient

The nurse gives medication to the patient in the correct dosage and confirms that he or she is taking the medication. Compliance is maintained throughout the hospital stay because it is "managed by the nurses," so to speak, by simply giving the medication on the spot. However, patients are unlikely to be fully aware of their medications if they are taking them at a set time [17], since patients will no longer have to worry about the dosage and administration of their medications, which is unlikely to improve adherence. It has also been reported that poor adherence is related to the occurrence of adverse effects, the number of medications, and the number of doses [19]. Patients with cognitive impairment are more likely to fall and have other problems than patients with normal cognitive function due to inadequate drug knowledge and understanding of dosage and administration [20]. In the present study, after adjusting for confounding factors such as the number of medications and cognitive functioning, we found that the number of medication instructions was associated with successful continued medication self-management. Therefore, pharmacists should strive to help patients understand the significance of their own medications and repeatedly instruct them to manage their own medication by themselves. We believe that allowing patients to manage their own medications during their hospitalization can improve their willingness to take their medications and help them return to society. Patient supervision by pharmacists is effective in improving clinical laboratory values and medication compliance [21].

The pharmacists in this study used a drug information form to carefully explain the significance and typical adverse effects of each drug in plain language to improve the patients' drug knowledge. The cut-off value for episodes of medication instruction associated with continued medication self-management was 5 . As a rule, the interval for medication instruction was once a week. However, patients were instructed every time there was a change in medications or dosage and administration or the patient's condition deteriorated. For patients with polypharmacy, we suggested to the physician to reduce dosage or number of medications to prevent the occurrence of adverse effects. We have worked to improve adherence by bundling medications into a 1-dose package, if possible, so that self-management can continue. Medication instructions help patients to acquire correct knowledge about medications and to understand the importance and significance of proper medication use. It is presumed that this instruction reduces anxiety about taking medications and enables patients to continue selfmanagement.

FIM-C on admission and aging were also associated with continued medication self-management. For FIM-C at admission, we demonstrated that higher ADLs related to cognition at admission positively affected continued medication self-management. A previous report showed that older adults with low cognitive functioning have lower medication self-management behaviors, which has been shown to contribute to poor medication compliance $[22,23]$. The results of this study differed from those previously reported in that cognitive ADL was associated with medication self-management rather than cognitive function. However, the results of the present study supported previous reports, given cognitive scales such as the Mini-Mental State Examination and the FIM$C$ have been shown to be significantly correlated [24].

Aging has a negative impact on continued medication self-management. Given aging is associated with decreased medication adherence caused by factors such as cognitive decline and dysphagia [25], it can be an important factor when considering continued medication self-management. A previous study reported a negative correlation between aging and medication self-management [26]; the results of the present study support the previous report.

Hypertension was also associated with continued medication self-management. Many patients with hypertension aim to actively make lifestyle modifications on their own to control blood pressure. Therefore, it is necessary for them to manage their daily activities. In addition, medical professionals routinely provide guidance to hypertensive patients on how to improve their lifestyle. Thus, it was considered that hypertensive patients were generally more aware of self-management and medication self-management, which is considered to be part of their daily lives.

Our study has several limitations. First, because this was a retrospective observational study, a causal relationship between the continuation of medication self-management and medication instructions by a pharmacist could not be established. Therefore, a multicenter prospective study is needed to generalize this study. Second, the lesion site is associated with the self-management of patients with 
cerebrovascular disease [27]; however, the lesion site in cerebrovascular disease was not considered. Third, the intervals between medication instructions have not been fully investigated. However, at this facility, the highest numbers of medication instructions were only two to three times per week and never five consecutive times. Fourth, the impact of one-dose package on medication management was not considered. Finally, the contents of rehabilitation were not considered.

\section{Conclusions}

Our findings revealed that pharmacist medication instructions might be associated with continued medication self-management during hospitalization. Our findings will be useful in the convalescent rehabilitation ward, where many patients live in their home after discharge. Future studies should examine whether pharmacist medication instructions lead to successful medication self-management.

\section{Abbreviations}

ADL: activities of daily living; BMl: body mass index; CRP: C-reactive protein; FIM: functional independence measure; FIM-C: functional independence measure-cognitive; FIM-M: functional independence measure-motor; FIM$\mathrm{T}$ : functional independence measure-total; HDS-R: Hasegawa dementia rating scale-revised; J-RACT: Japanese Regimen Adherence Capacity Tests; MCC: Matthews Correlation Coefficient; RCS: Regimen comprehension scale; ROC: Receiver Operating Characteristic

\section{Acknowledgements}

The authors thank the manager of Ogaki Tokushukai Hospital who agreed for this study to take place.

\section{Authors' contributions}

EK: conception and design, performing field work, data analysis and interpretation, preparation of draft manuscript and revising the manuscript, and overall scientific management. $\mathrm{HE}, \mathrm{HH}, \mathrm{SH}, \mathrm{CK}, \mathrm{YK}$, and TY: collecting data. NY: giving scholarly input in field work, providing critique, and overall scientific management. All authors have read and approved the final manuscript.

\section{Funding}

There are no funding sources for this manuscript.

\section{Availability of data and materials}

All data generated or analyzed during this study are included in this published article.

\section{Ethics approval and consent to participate}

The present study was performed in accordance with the Declaration of Helsinki, and was approved by the Joint Ethics Committee of the Tokushukai Group.

\section{Consent for publication}

No applicable.

\section{Competing interests}

No potential conflicts of interest were disclosed.

\section{Author details}

${ }^{1}$ Department of Pharmacy, Teikyo University School of Medicine University Hospital, 2-11-1 Kaga, Itabashi-ku, Tokyo 173-8606, Japan. ${ }^{2}$ Department of Pharmacy, Ogaki Tokushukai Hospital, 6-85-1 Hayashi-chou, Ogaki, Gifu 503-0015, Japan. 'Laboratory of Hospital Pharmacy, School of Pharmacy, Teikyo University, 2-11-1 Kaga, Itabashi-ku, Tokyo 173-8606, Japan.
Received: 20 October 2020 Accepted: 15 February 2021

Published online: 03 March 2021

\section{References}

1. Kose E, Maruyama R, Okazoe S, Hayashi H. Impact of Polypharmacy on the rehabilitation outcome of Japanese stroke patients in the convalescent rehabilitation Ward. J Aging Res. 2016;2016:7957825.

2. Fitten L, Coleman L, Siembieda DW, Yu M, Ganzell S. Assessment of capacity to comply with medication regimens in older patients. J Am Geriatr Soc. 1995:43:361-7.

3. Bushnell CD, Olson DM, Zhao X, Pan W, Zimmer LO, Goldstein LB, et al. Secondary preventive medication persistence and adherence 1 year after stroke. Neurology. 2011;77:1182-90.

4. Jamison J, Graffy J, Mullis R, Mant J, Sutton S. Barriers to medication adherence for the secondary prevention of stroke: A qualitative interview study in primary care. Br J Gen Pract. 2016;66:e568-76.

5. Satink T, Cup EH, de Swart BJ, Nijhuis-van der Sanden MW. How is selfmanagement perceived by community living people after a stroke? A focus group study. Disabil Rehabil. 2015;37:223-30.

6. Satink T, Josephsson S, Zajec J, Cup EH, de Swart BJ, Nijhuis-van der Sanden MW. Self-management develops through doing of everyday activities--a longitudinal qualitative study of stroke survivors during two years poststroke. BMC Neurol. 2016;16:221.

7. Chumney D, Nollinger K, Shesko K, Skop K, Spencer M, Newton RA. Ability of functional Independence measure to accurately predict functional outcome of stroke-specific population: systematic review. J Rehabil Res Dev. 2010;47:17-29.

8. Ottenbacher KJ, Hsu Y, Granger CV, Fiedler RC. The reliability of the functional independence measure: a quantitative review. Arch Phys Med Rehabil. 1996;77:1226-32.

9. Shiomi T, Kurono S, Sanada S, Okada H, Kobayashi T. Elderly Patient's capacity for medication regimens evaluation by Japanese regimen adherence capacity tests (J-RACT). Jpn J Clin Pharmacol Ther. 1997;28: 793-800

10. Shiomi T, Okada H, Sanada S, Kurono S, Kobayashi T. Development of a Rejimen comprehension scale. Jpn J Geriat. 1997;34:209-14.

11. Chicco D, Jurman G. The advantages of the Matthews correlation coefficient (MCC) over F1 score and accuracy in binary classification evaluation. BMC Genomics. 2020;21:1-13.

12. Kose $E$, Wakabayashi $H$. Rehabiritation pharmacotherapy: a scoping review. Geriatr Gerontol Int. 2020;20:655-63.

13. Kose E, Hirai T, Seki T, Hayashi H. Role of potentially inappropriate medication use in rehabilitation outcomes for geriatric patients after strokes. Geriatr Gerontol Int. 2018;18:321-8.

14. Kose $E$, Hirai T, Seki T, Hayashi H. The association of increased drugs use with activities of daily living and discharge outcome among elderly stroke patients. Int J Clin Pharm. 2018;40:599-607.

15. Kose E, Hirai T, Seki T, Hidaka S, Hamamoto T. Anticholinergic load negatively correlates with recovery of cognitive activities of daily living for geriatric patients after stroke in the convalescent stage. J Clin Pharm Ther. 2018;43:799-806.

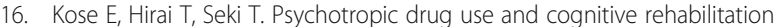
practice for elderly patients. Int J Clin Pharm. 2018;40:1292-9.

17. Yamanishi $Y$, Omori Y, Yamanishi N, Ogawa M, Kojima C, Tsukahara R, et al. Usefulness of medication Management in Inpatients with schizophrenia. Jpn J Pharm Health Care Sci. 2008:34:1097-9.

18. Sendt KV, Tracy DK, Bhattacharyya S. A systematic review of factors influencing adherence to antipsychotic medication in schizophreniaspectrum disorders. Psychiatry Res. 2015;225:14-30.

19. Lambert M, Conus P, Eide P, Mass R, Karow A, Moritz S, et al. Impact of present and past antipsychotic side effects on attitude toward typical antipsychotic treatment and adherence. Eur Psychiatry. 2004;19:415-22.

20. Cadilhac DA, Kilkenny MF, Srikanth V, Lindley RI, Lalor E, Osborne RH, et al. Do cognitive, language, or physical impairments affect participation in a trial of self-management programs for stroke? Int J Stroke. 2016:11:77-84.

21. Al-Rashed SA, Wright DJ, Roebuck N, Sunter W, Chrystyn H. The value of inpatient pharmaceutical counselling to elderly patients prior to discharge. Br J Clin Pharmacol. 2002;54:657-64.

22. Raehl CL, Bond CA, Woods T, Patry RA, Sleeper RB. Individualized drug use assessment in the elderly. Pharmacotherapy. 2002;22:1239-48. 
23. Okuno J, Yanagi H, Tomura S. Is cognitive impairment a risk factor for poor compliance among Japanese elderly in the community? Eur J Clin Pharmacol. 2001;57:589-93.

24. Zwecker M, Levenkrohn S, Fleisig Y, Zeilig G, Ohry A, Adunsky A. Minimental state examination, cognitive FIM instrument, and the Loewenstein occupational therapy cognitive assessment: relation to functional outcome of stroke patients. Arch Phys Med Rehabil. 2002;83:342-5.

25. Osterberg L, Blaschke T. Adherence to medication. N Engl J Med. 2005;353: 487-97.

26. Fujihara H, Kogo M, Saito I, Kawate N, Mizuma M, Suzuki H, et al. Development and evaluation of a formula for predicting introduction of medication self-management in stroke patients in the Kaifukuki rehabilitation ward. J Pharm Health Care Sci. 2017;3:2.

27. Fujihara H, Goto K, Higashino M, Nakamura S, Tanaka E, Sunaga T, et al. The impact of lesion location on medication self-management ability in patients with cerebrovascular disease. JJCRS. 2020;11:21-7.

\section{Publisher's Note}

Springer Nature remains neutral with regard to jurisdictional claims in published maps and institutional affiliations.

Ready to submit your research? Choose BMC and benefit from:

- fast, convenient online submission

- thorough peer review by experienced researchers in your field

- rapid publication on acceptance

- support for research data, including large and complex data types

- gold Open Access which fosters wider collaboration and increased citations

- maximum visibility for your research: over $100 \mathrm{M}$ website views per year

At BMC, research is always in progress.

Learn more biomedcentral.com/submissions 